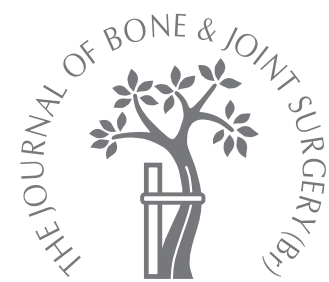

CASE REPORT

\title{
Operative treatment of hip impingement caused by hypertrophy of the anterior inferior iliac spine
}

HL. Pan,

K. Kawanabe,

H. Akiyama,

K. Goto,

E. Onishi,

T. Nakamura

From Harbin Medical

University,

Heilongjiang

Province, China

HL. Pan, MD, PhD

Orthopaedic Surgeon

Department of Orthopaedic

Surgery,

The Affiliated No.2, Hospital of

Harbin Medical University,

Heilongjiang Province 150086

China.

K. Kawanabe, $\mathrm{MD}, \mathrm{PhD}$ Associate Professor

H. Akiyama, MD, PhD,

Orthopaedic Surgeon

K. Goto, MD, PhD

Orthopaedic Surgeon

E. Onishi, MD, Orthopaedic

Surgeon

T. Nakamura, MD, PhD,

Professor

Department of Orthopaedic

Surgery,

Graduate School of Medicine Kyoto University, Shogoin,

Kawahara-cho 54, Sakyo-ku,

Kyoto 606-8957, Japan.

Correspondence should be sent to $\mathrm{Dr}$ HL. Pan; e-mail: panhaile2002@hotmail.com

(C)2008 British Editorial Society of Bone and Joint Surgery doi:10.1302/0301-620X.90B5 $20005 \$ 2.00$

$J$ Bone Joint Surg $[B r]$ 2008; 90-B:677-9.

Received 25 July 2007;

Accepted after revision 22

November 2007

\begin{abstract}
A 30-year-old man presented with pain and limitation of movement of the right hip. The symptoms had failed to respond to conservative treatment. Radiographs and CT scans revealed evidence of impingement between the femoral head-neck junction and an abnormally large anterior inferior iliac spine. Resection of the hypertrophic anterior inferior iliac spine was performed which produced full painless restoration of function of the hip.

Hypertrophy of the anterior inferior iliac spine as a cause of femoro-acetabular impingement has not previously been described.
\end{abstract}

Femoro-acetabular impingement is currently considered to be one of the causes for progressive degenerative damage to the articular cartilage of the hip producing osteoarthritis. ${ }^{1-2}$ It has been attributed to structural abnormalities involving both the acetabulum and femoral head-neck junction. ${ }^{3-5}$ Repeated impingement between the anterior femoral head-neck junction and anterior aspect of the acetabulum has been shown to lead to not only chronic groin pain but also dysfunction of the hip joint, especially in young active patients in whom arthroscopic treatment might be appropriate. ${ }^{6-8}$ However, impingement between the femoral head-neck junction and an abnormally hypertrophic anterior inferior iliac spine has, to our knowledge, not been reported.

We report the clinical presentation, radiological and CT findings and operative treatment of a patient who was referred with groin pain.

\section{Case report}

A 30-year-old man who had been an enthusiastic football player and athlete since school age presented with a ten-year history of right groin pain. The pain was usually induced by jumping and running but could develop after prolonged walking. He had been treated with nonsteroidal anti-inflammatory drugs and physiotherapy, but without benefit.

There was no previous medical history and no history of trauma to the hip or symptoms from the lumbar spine or contralateral hip.

He weighed $71 \mathrm{~kg}$ and was $170 \mathrm{~cm}$ tall. There was tenderness in the right groin with only $90^{\circ}$ of hip flexion and marked restriction of internal rotation. With the hip flexed to $90^{\circ}$ with adduction internal rotation provoked severe groin pain.

The pelvic anteroposterior (AP) radiograph showed an abnormal appearance just above the anterior superior rim of the right acetabulum which extended inferiorly (Fig. 1). In addition there was an abnormality at the femoral headhip. The axial CT scan and a three-dimensional reconstruction revealed hypertrophy of the

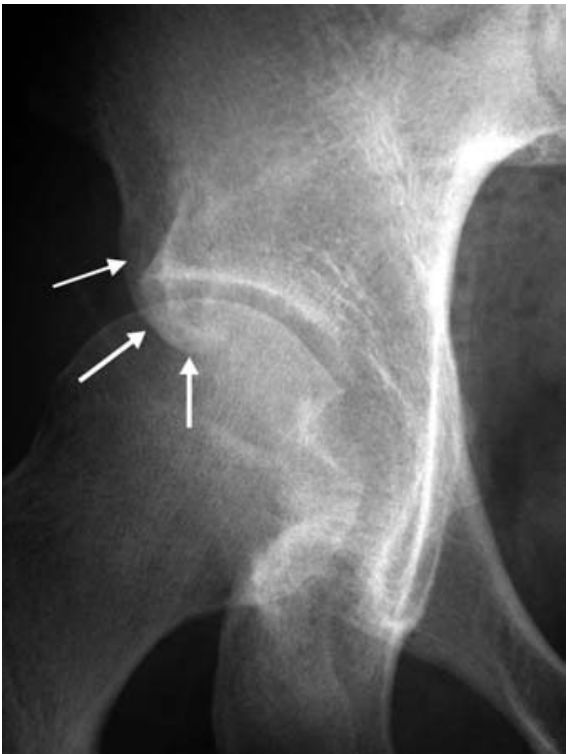

Fig. 1

Anteroposterior radiograph of the right hip of a 30-year-old man with a hypertrophic anterior inferior iliac spine (arrows). neck junction and an altered offset to the right 


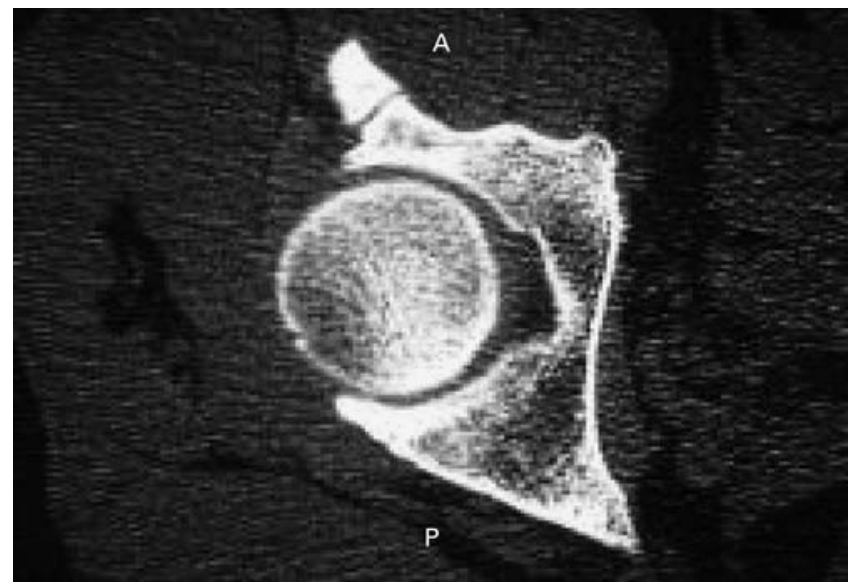

Fig. 2a

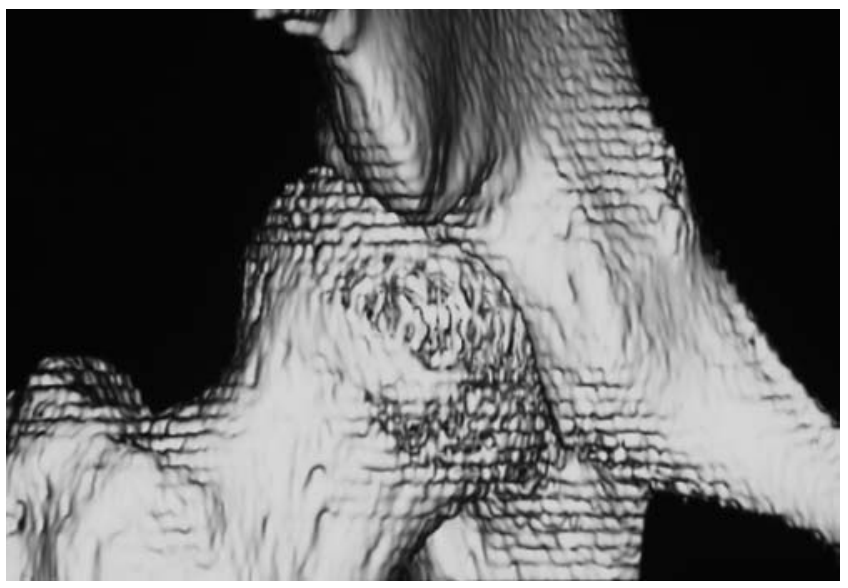

Fig. $2 b$

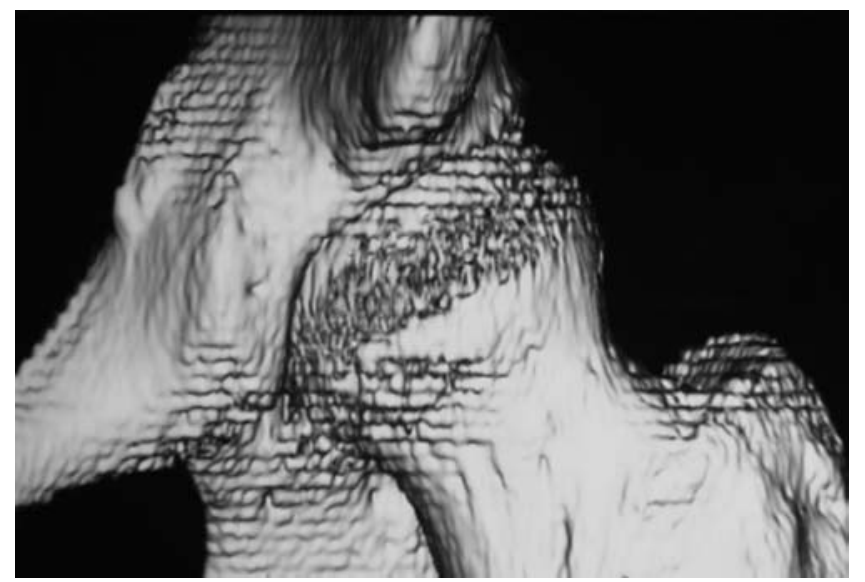

Fig. 2c

a) A pre-operative CT scan and b) three-dimensional CT reconstruction of the right hip demonstrating the abnormal enlargement of the anteriorinferior iliac spine. c) The CT reconstruction of the left hip shows the normal anatomy for comparison. (A, anterior; $P$, posterior).

anterior inferior iliac spine with a pseudarthrosis through its base. The left hip itself was normal (Fig. 2).

Arthroscopy of the right hip showed normal cartilage on the femoral head and acetabulum and no labral damage. The hip was explored using a Smith-Petersen approach. Through the interval between the rectus femoris and the gluteus medius, the joint capsule was identified. Part of the tensor fascia lata and gluteus medius was detached from the iliac crest to enhance the display of the joint capsule. The reflected and straight heads of rectus femoris were detached from their origins and to confirm the arthroscopic findings an arthrotomy was performed. The hypertrophic anterior inferior iliac spine was noted with a pseudarthrosis at its base. Impingement occurred between the hypertrophic anterior inferior iliac spine and the anterior aspect of the femoral head/neck when the hip was flexed to nearly $90^{\circ}$. The hypertrophic portion of anterior inferior iliac spine was resected through the pseudarthrosis to leave a normal sized anterior inferior iliac spine which did not cause any impingement.
Post-operative CT scans confirmed that the hypertrophic part of the anterior inferior iliac spine had been satisfactorily resected (Fig. 3).

We did not advise any restriction of movement postoperatively and asked the patient to exercise gradually increasing his weight-bearing. He walked unaided two weeks after operation. He recovered $120^{\circ}$ of hip flexion and a normal range of internal rotation. The groin pain and limp resolved at five weeks post-operatively and he returned to full normal activities.

\section{Discussion}

Femoro-acetabular impingement was first described as a syndrome in $1991^{9,10}$ and has been proposed as a major risk factor for the development of degenerative disease of the hip. ${ }^{3,11}$

The characteristic finding is limitation of flexion and internal rotation with associated groin pain. Impingement can cause structural changes to the hip joint, including a 


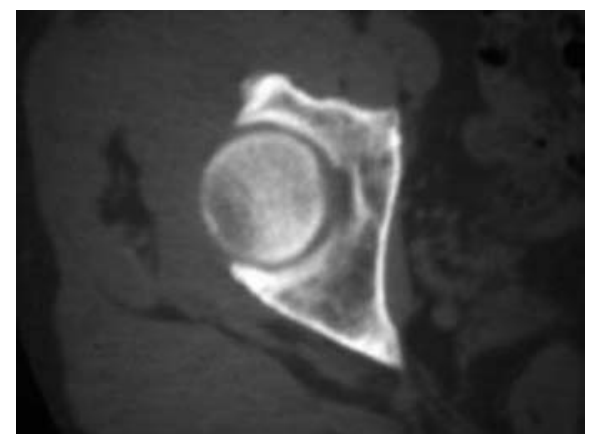

Fig. 3

A post-operative CT scan following resection of the hypertrophic anterior inferior iliac spine.

labral tear, acetabular cartilage damage, a decreased anterior femoral head-neck ratio and the formation of a bone cyst in the femoral neck. ${ }^{12,13}$ Although abnormalities of the anterior inferior iliac spine have been described previously we could not find any reports of associated impingement. ${ }^{14,15}$

The anterior inferior iliac spine is the origin of the main head of the rectus femoris which is contracted in vigorous sport such as pursued by our patient. Avulsion fractures resulting from excessive stress on the anterior inferior iliac spine, a hypertrophic anterior inferior iliac spine, have been described. ${ }^{16-19}$ We suspect that the formation of a traction spur was the main reason for the hypertrophy of the anterior inferior iliac spine in our patient.

No benefits in any form have been received or will be received from a commercial party related directly or indirectly to the subject of this article.

\section{References}

1. Mardones RM, Gonzalez C, Chen 0, et al. Surgical treatment of femoro-acetabular impingement: evaluation of the effect of the size of the resection. J Bone Joint Surg [Am] 2006;88-A (Suppl 1):84-91.
2. Ganz R, Parvizi J, Beck M, et al. Femoroacetabular impingement: a cause for osteoarthritis of the hip. Clin Orthop 2003;47:112-20.

3. Beck M, Kalhor M, Leunig M, Ganz R. Hip morphology influences the pattern of damage to the acetabular cartilage: femoroacetabular impingement as a cause of early osteoarthritis of the hip. J Bone Joint Surg [Br]2005;87-B:1012-18.

4. Tanzer M, Noiseux N. Osseous abnormalities and early osteoarthritis: the role of hip impingement. Clin Orthop 2004;429:170-7.

5. Beaulé PE, Le Duff MJ, Zaragoza E. Quality of life following femoral head-neck osteochondroplasty for femoroacetabular impingement. J Bone Joint Surg [Am] 2007;89-A:773-9.

6. Crawford JR, Villar RN. Current concepts in the management of femoroacetabular impingement. J Bone Joint Surg [Br] 2005;87-B:1459-62.

7. Ganz R, Gill TJ, Gautier E, et al. Surgical dislocation of the adult hip: a technique with full access to the femoral head and acetabulum without risk of avascular necrosis. J Bone Joint Surg [Br] 2001;83-B:1119-24.

8. Ilizaliturri VM Jr, Nossa-Barrera JM, Acosta-Rodriguez E, Camecho-Galindo J. Arthroscopic treatment of femoroacetabular impingement secondary to paediatric hip disorders. J Bone Joint Surg [Br] 2007;89-B:1025-30.

9. Klaue K, Eurnin CW, Ganz R. The acetabular rim syndrome: a clinical presentation of dysplasia of the hip. J Bone Joint Surg [Br] 1991;73-B:423-9.

10. Ganz R, Bamert P, Hausner P, Isler B, Vreve F. Cervico-acetabular impingement after femoral neck fracture. Unfallchirurg 1991;94:172-5 (in German)

11. Günther KP, Hartmann A, Aikele P, Aust D, Ziegler J. Large femoral-neck cysts in association with femoroacetabular impingement: a report of three cases. $J$ Bone Joint Surg [Am] 2007;89-A:863-70.

12. Mardones RM, Gonzalez $\mathbf{C}$, Chen $\mathbf{0}$, et al. Surgical treatment of femoroacetabular impingement: evaluation of the effect of the size of the resection. J Bone Joint Surg [Am] 2005;87-A:273-9.

13. MacDonald SJ, Garbuz D, Ganz R. Clinical evaluation of the symptomatic young adult hip. Semin Arthroplasty 1997:8:3-9.

14. Resnick JM, Carrasco CH, Edeiken J, et al. Avulsion fracture of the anterior inferior iliac spine with abundant reactive ossification in the soft tissue. Skeletal Radiol 1996;25:580-4.

15. Rajasekhar C, Kumar KS, Bhamra MS. Avulsion fractures of the anterior inferior iliac spine: the case for surgical intervention. Int Orthop 2001;24:364-5.

16. de Jong VM, van den Broek CM. Diagnostic image (263): a soccer playing girl with a painful hip. Ned Tijdschr Geneeskd 2006;150:424.

17. Yildiz C, Yildiz Y, Ozdemir MT, Green D, Aydin I. Sequential avulsion of the anterior inferior iliac spine in an adolescent long jumper. Br J Sports Med 2005;39:e31

18. Yildiz C, Aydin T, Yildiz Y, Kalyon TA, Basbozkurt M. Anterior inferior iliac spine apophyseal avulsion fracture. J South Orthop Assoc 2003;12:38-40.

19. Rossi F, Dragoni S. Acute avulsion fractures of the pelvis in adolescent competitive athletes: prevalence, location and sports distribution of 203 cases collected. Skeletal Radiol 2001;30:127-31. 